\title{
João Mota e a encenação de vozes
} Maria Helena Serôdio

\section{Todos os que caem, de Samuel Beckett, enc. João Mota, Comuna - Teatro de Pesquisa, 2006 (Maria do Céu Guerra),} fot. Pedro Soares.

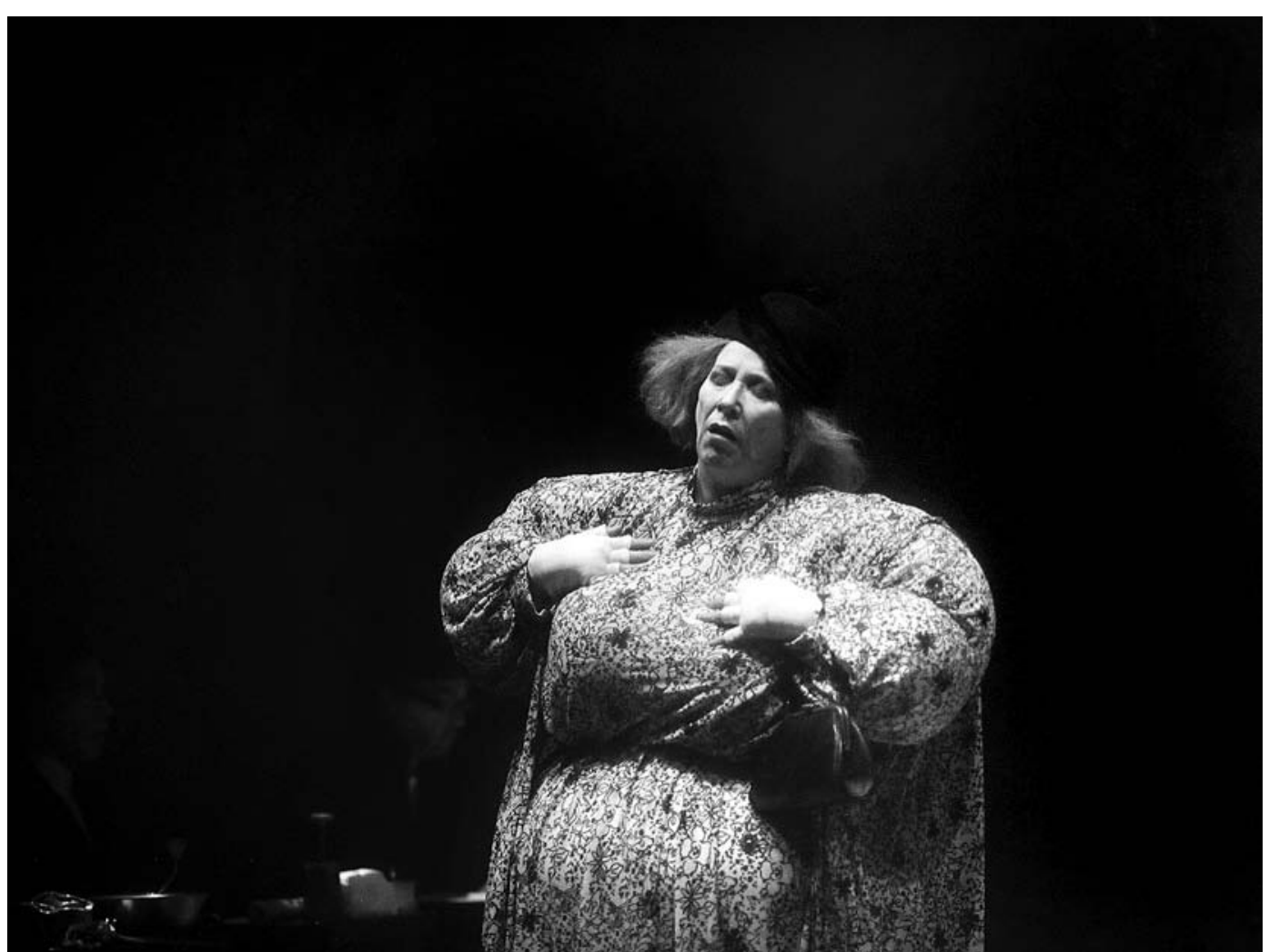

Declarámos na Nota para a Imprensa que o júri da APCT atribuia uma Menção Especial a João Mota pela concepção cénica de Todos os que caem, o espectáculo sobre texto de Samuel Beckett produzido pela companhia que ele devotadamente dirige há 35 anos - A Comuna.

A sua concepção trazia à cena, com uma curiosa e inventiva plasticidade, o universo de Beckett, jogando de forma viva com o imaginário radiofónico - os seus signos materiais e o seu simbolismo.

Ao fazê-lo, João Mota marcou de forma original a sua primeira incursão no universo beckettiano, trabalhando um texto que originalmente foi concebido para a rádio (em 1956), e que, por isso mesmo, se oferecia como mais complexo na sua transposição cénica. E é justamente ao assumir esse traço originário, que o encenador fez irromper na Sala das Novas Tendências do seu teatro alguns aspectos visuais e sonoros do que poderiam ser os procedimentos de um estúdio de rádio. Por aí o encenador remetia, afinal, de forma consequente, não apenas para a ficção de Beckett, mas também para uma realidade - técnica e artística com que João Mota, ainda miúdo (com cerca de 8 anos de idade), contactou, quando se estreou num programa infantil da Emissora Nacional.
Inventou um espaço rectangular que se revelava ao público através de uma cortina de gaze transparente (telão em rede) e repartiu a cena entre uma zona central, onde circulavam os actores quando em personagem, e uma outra (de ambos os lados) em que eles se sentavam frente a uma pequena mesa de trabalho quando participavam como produtores de som. Esse era, então, o lugar cativo de quem ia construindo sonoridades - das galinhas, das vacas, da mula, da bicicleta, etc. - a partir de objectos artesanais, tornando óbvia a artificialidade dessa evocação da vida rural. A envolver a tonalidade narrativa, que atravessa a peça de Beckett, esteve a voz offde Luís Filipe Costa, assegurando a ligação à nossa memória das noites de teatro ou a de um locutor que associamos a importantes intervenções sobre a realidade politica do antes e depois do 25 de Abril.

Outros travejamentos essenciais deste espectáculo, concebido por João Mota, eram visíveis na imagem cénica que compunha: no recorte das figuras - com

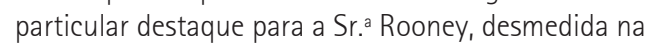
sua gordura e reumatismo, que a colocariam na galeria dos desenhos e esculturas de um artista como Botero 


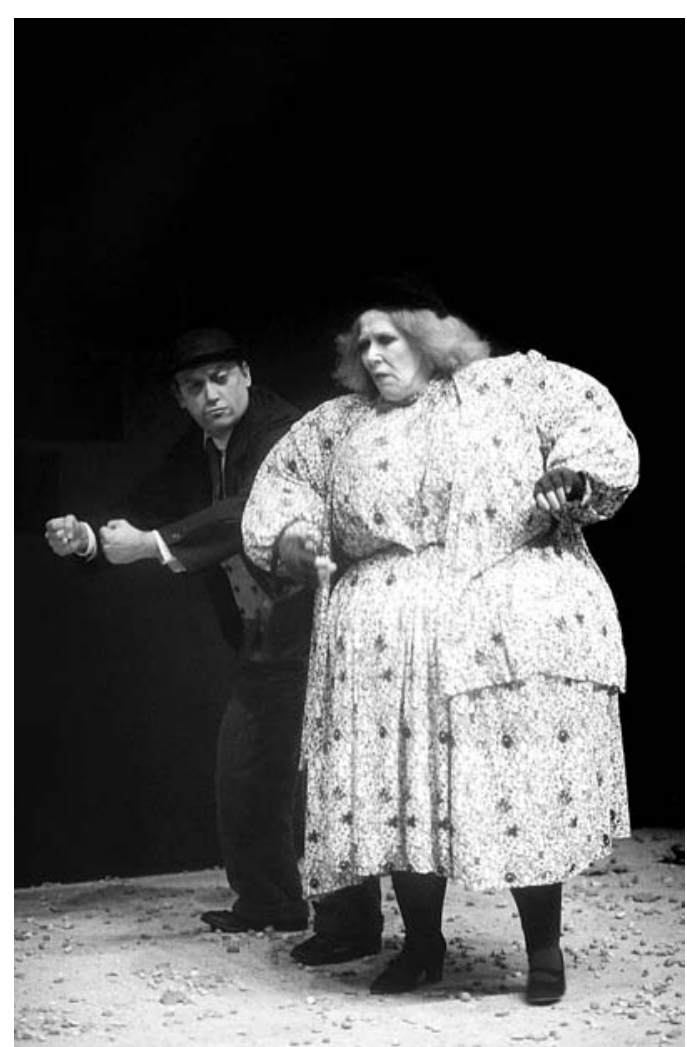

-, nos traços expressivos dos chapéus, que todos usavam, na lisura eloquente dos figurinos, na exagerada maquilhagem (com um toque quase expressionista), na pantomima a que recorrem, enfim, no jogo interpretativo, em geral.

Resultavam, de facto, notáveis os trabalhos de expressiva fisicalidade dos actores, sem que isso os levasse à paródia simples, mantendo, pelo contrário, a tensão entre o esforço e a sua repetida "desvalorização". Reconduziam, assim, a cena à ideia de um jogo teatral subtil, aliciante, que - evocando de perto as formas ficcionais e estilísticas de Beckett - se desdobrava entre a compaixão e a troça.

No conjunto das interpretações destacava-se a actriz Maria do Céu Guerra num trabalho de excelente composição, não só na construção exterior da figura, mas também no arrebatamento interior (e sua paródia, simultaneamente), na desmesura retórica de quem permanentemente se cita em lapidares declarações públicas e, enfim, no riso entre o derrisório e o demencial que é a sua máscara mais consentida. Mas, no geral, todo o elenco, que recriava o universo humano daquela imaginada vilória irlandesa - Boghill -, apresentava um trabalho depurado e convergia numa sustentada criação de um mundo estranho e todavia reconhecivel nos pecadilhos humanos daquela exuberante Sr. ${ }^{a}$ Rooney que se arrasta a caminho da estação de comboios para se encontrar com o marido cego e assim fazer-Ihe uma surpresa no dia do seu aniversário.

E nesta evocação sensivel, João Mota mostrava mais uma vez, um dos traços da sua prática artística e pedagógica, citado recentemente por Eugénia Vasques no seu livro João Mota, o pedagogo teatral: "O segredo do criador consiste em olhar o lado oculto das coisas. Ver o que poucos vêem"2.

Aqui tratava-se de conferir visibilidade às vozes, 0 que o encenador cumpriu de forma inteligente e sensivel, não omitindo o lado paródico que se poderia reconhecer no perfil picaresco da figura principal, mas não descartando também uma compadecida visão daquela frágil humanidade ali convocada.

Foi assim que o espectáculo, arquitectando uma atmosfera de realismo sonâmbulo, aliava a fantasia de uma ruralidade artisticamente fabricada com um humaníssimo grotesco, dando prova de uma imaginativa solução cénica que João Mota concebeu de forma inesquecivel na sua Comuna e que o júri da Associação Portuguesa de Críticos de Teatro merecidamente distinguiu.

\section{Todos os que caem, de Samuel Beckett, enc. João Mota, Comuna - \\ Teatro de Pesquisa, 2006 (Álvaro Correia e Maria do Céu Guerra), fot. Pedro Soares.}

\footnotetext{
2 Eugénia Vasques, João Mota, o pedagogo teatral, Lisboa, Colibri \&t Instituto Politécnico de Lisboa, 2006, p. 103.
} 